\section{Ursolic and Oleanolic Acid in 'Aroma' Apple Peel as Affected by Rootstock, Harvest Maturity, and Storage Method}

\author{
Yanrong Lv ${ }^{1}$, Ibrahim I. Tahir, and Marie E. Olsson \\ Department of Plant Breeding, Swedish University of Agricultural Sciences, \\ P.O. Box 101, SE-23053, Alnarp, Sweden
}

\begin{abstract}
Additional index words. triterpene, controlled atmospheric storage, semi-dwarfing 'MM.106', dwarfing 'M.9'
\end{abstract}

\begin{abstract}
Apples contain substances with health-promoting properties, among them, triterpenes, including oleanolic acid (OA) and ursolic acid (UA), which are thought to have anti-inflammatory activity as well as inhibiting initiation, promotion, and metastasis of cancer. This study evaluated effects of harvest time, rootstock, and storage method on two major triterpenes in apple peel, to enhance the understanding of the relative importance of cultivation and environmental factors influencing triterpene concentration. $O A$ and $U A$ concentrations in the semi-dwarfing 'MM.106' rootstock apples were significantly higher than in the dwarfing 'M.9' rootstock apples at the majority of harvest times over the 2 years of investigations. In 2012 at harvest time, highest concentrations of $\mathrm{OA}$ and $\mathrm{UA}$ in 'MM.106' rootstock apples were 63.4 and $416.3 \mu \mathrm{g} \cdot \mathrm{cm}^{-2}$, respectively, while they were 59.7 and $380.9 \mu \mathrm{g} \cdot \mathrm{cm}^{-2}$, respectively, in 'M.9' rootstock apples. UA remained fairly stable in most cases during storage, and no difference was found between regular atmosphere storage and controlled atmospheric (CA) storage. OA concentration decreased after harvest time. Furthermore, OA showed different responses to regular atmosphere storage and $\mathrm{CA}$ storage, and year-to-year difference was also observed. The two rootstocks showed only slight differences in the effect on total soluble solids (TSS) and fruit color, while the titratable acidity (TA) in apples from trees on 'M.9' rootstock had lower levels in most cases at the third harvest time as compared with apples from trees on 'MM.106' rootstock. OA concentration was positively correlated with UA concentration both directly at harvest and after storage. $O A$ and UA concentrations were positively correlated with TA and TSS, while they were negatively correlated with red color.
\end{abstract}

Apples play a significant role in the diet in different countries around the world. Epidemiological studies have shown that consumption of apples is linked to reduced risk of cardiovascular disease, some cancers, asthma, and Alzheimer's disease (Hyson, 2011). Health-promoting properties have been attributed to the presence of a range of secondary metabolites, including triterpenes. OA (3ß-hydroxy-olean-12-en-28-oic acid) and its isomer, UA (3ß-hydroxy-ursan-12en-28-oic acid, UA), are the two major triterpenes in apple peel (Cefarelli et al., 2006). OA and UA are commonly found in the cuticular waxes of fruit and leaves and they are important components of the wax (Koch and Ensikat, 2008; Qi et al., 2006). Along with antioxidative activity, these compounds have also been reported to have anti-inflammatory activity, and inhibit initiation, promotion, and metastasis of cancer (Shanmugam et al., 2013). UA and its

\footnotetext{
Received for publication 23 Oct. 2015. Accepted for publication $2 \mathrm{Feb} .2016$.

We thank Karl-Erik Gustavsson for technical assistance of the HPLC analysis and the storage management, and we also thank Jan-Eric Englund for the statistic calculation suggestions.

${ }^{1}$ Corresponding author. E-mail: yanrong.lv@slu.se.
}

factors, rootstock controls tree size (Webster, 2001), regulates mineral uptake and leaf mineral composition (Fallahi et al., 2001), and affects hydraulic resistance, water use of scion, and fruit quality (Cohen and Naor, 2002; Cohen et al., 2007; Fallahi et al., 2002). Furthermore, they may have resistance to soil-transmitted diseases (Modgil et al., 2012) and fire blight (Kaja et al., 2015). Many suggestions have been made to explain the separate features in the rootstocks that exert these differences such as the characteristics of the bark, production and movement of different plant hormones, and top-root relationships (Ferree and Warrington, 2003; Rom and Carlson, 1987). Dwarfing rootstock 'M.9' and semi-dwarfing rootstock 'MM.106' are commonly used in apple orchards in many countries. 'M.9' rootstock was introduced as one of the Malling apple rootstock series, a result of a successful trial in England, which evaluated rootstocks of different origin in the early 20th century. 'M.9' was a chance seeding found in France. The Malling series was later followed by the Malling-Merton rootstock series, from which 'MM.106' originate. This rootstock is a cross between 'M.1' (Malling series) and 'Northern Spy' (Ferree and Warrington, 2003; Rom and Carlson, 1987). In 'M.9', more limited supply of water and minerals was found as compared with 'MM.106'. Plant hormones levels vary between these two rootstocks. Auxin and cytokinin were lower in 'M.9', whereas the level of abscisic acid was found to be higher than in 'MM.106' (Tromp et al., 2005). Although compounds with health benefits have been investigated more frequently during recent years, information about the effect of different cultivation factors, such as the rootstock, on triterpene concentration is still lacking.

Fruit ripening is a complex process, which includes a series of biochemical, physiological, and structural changes (Lelièvre et al., 1997). Apple fruit will experience various metabolic changes during maturation and storage, such as the change of texture (Johnston et al., 2001), anthocyanin and phenolic concentration (Burda et al., 1990; Ju and Bramlage, 1999), antioxidant activity (Ju and Bramlage, 1999), and wax composition (Veraverbeke et al., 2001). The total phenolics concentration in apple peel showed variable responses to storage, including an increase, decrease, or no change (Golding et al., 2001; Kevers et al., 2011; Rössle et al., 2010). Triterpenes are secondary metabolites and important components in the wax of the cuticle. A study on grapes showed that the young grapes had higher level of triterpenoids, which gradually decreased during ripening, but the neutral triterpenoids showed a slight increase (Pensec et al., 2014). However, changes in the triterpene concentration of apples during the ripening on the tree and after different storage methods have not yet been thoroughly investigated.

The aim of this study was to evaluate the effects of harvest time, rootstock, and storage method on two major triterpenes in apple 
peel, OA and UA, to enhance the understanding of the compositional evolution of triterpenes during apple fruit ripening and postharvest storage, which can provide valuable knowledge for prebreeding projects and thereby a sound basis for applied breeding programs. In addition, correlations between different quality parameters were determined.

\section{Materials and Methods}

Fruit material. Twenty-four 'Aroma' trees, on two different rootstocks (12 trees on a semi-dwarfing 'MM.106' and 12 trees on a dwarfing 'M.9'), were randomly chosen and divided into three replicate blocks by row, with each block containing four trees in an IP-orchard in Kivik, southeastern Sweden

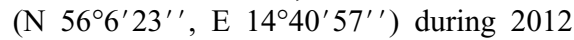
and 2013 seasons. Trees had been planted in 1998 and trained as slender spindle. A similar orchard management program, including fertigation, mechanical weed control, and integrated pest management was applied. Trees were not thinned because they showed an acceptable yield and fruit size as well as very slight differences in their crop load.

Fruit were harvested at three times as following: early harvest on 12 Sept. 2012 and 10 Sept. 2013, middle harvest on 17 Sept. 2012 and 2013, and late harvest on 24 Sept. 2012 and 2013 from interior and perimeter of the canopies to show an actual presentation for the total tree yield. The three harvest times were used to reflect different fruit maturity, where the second harvest time was the commercial harvest maturity stage. Fruit harvesting date was estimated according to our experience with this cultivar (Tahir, 2006) using Streif Index ffirmness $\left[\mathrm{kg} \cdot \mathrm{cm}^{-2}\right] \times[$ total soluble solid $(\%) \times$ starch hydrolysis index (degradation stage) $\left.]^{-2}\right\}$ and previous results (Streif, 1996). Firmness was measured on opposite, peeled sides, at the equator of each fruit, by using a penetrometer (model FT 327; Effigi, Italy, plunger diameter of $11.1 \mathrm{~mm}$ and depth of $7.9 \mathrm{~mm}$ ) and results expressed as $\mathrm{kg} \cdot \mathrm{cm}^{-2}$. Starch index was evaluated by dipping a slide of equator part of apple in an iodine solution [15 g potassium iodide (Grade 99.5\%; MERCK, Darmstadt, Germany) and 6 g iodine (Grade: 99\%; VWR International AB, Stockholm, Sweden) per liter] for $1 \mathrm{~min}$, and using a grading scale where $1=$ full staining and $9=$ no stain (Ericsson, 1982). Fruit were harvested in the both seasons when their Streif Index was $0.22-0.24$ at the first harvest, $0.16-0.18$ at the second harvest, and $0.11-$ 0.13 at the third harvest. Six medium-sized apples were harvested uniformly (totally 72 apples at each harvest time for three blocks: 6 apples/tree $\times 4$ trees/block $\times 3$ blocks $=$ 72 apples). Each block and each replicate within each block were analyzed separately. Twenty-four apples of each block were separated. The 24 fruits of each block with three blocks (totally 72 apples) were then divided into three groups: first group of eight apples in each block (totally 24 apples in three blocks) were analyzed immediately, the second group of eight apples in each block (totally 24 apples in three blocks) were stored in regular atmospheric (RA) storage; $2-3{ }^{\circ} \mathrm{C}$ and $85 \%$ to $90 \%$ RH for 4 months in 2012 and 3 months in 2013, and the third group of eight apples in each block (totally 24 apples in three blocks) were stored in CA storage; $2{ }^{\circ} \mathrm{C}$ with $2 \mathrm{kPaO}_{2}$ and $2 \mathrm{kPa} \mathrm{CO}_{2}$ and $90 \% \mathrm{RH}$ for 4 months in 2012 and 3 months in 2013. CA storage conditions with computer-controlled gas composition were established in 350-L chambers (Nino-laboratory, Onsala, Sweden) $3 \mathrm{~d}$ before placing the apples in the chambers. Fruits were stored in RA and CA for the same time to clarify the actual storage effect. Skin color was measured on eight fruit in each block; the peel of these fruit was used for triterpenes analysis, while their flesh was used to measure the TSS, $\mathrm{pH}$, and TA.

Fruit color measurement. Color was measured at three locations on both the sunny (the red side of the fruit, facing away from the tree trunk) and shadow side (the green side of the fruit, facing the tree trunk) of fruit, using a Minolta Chroma meter CR-200 (Konica Minolta Inc., Osaka, Japan) with an 8-mmdiameter window. Color was expressed as hue angle $\left(\mathrm{h}^{\circ}\right)\left(\right.$ where $0^{\circ}=$ red-purple, $90^{\circ}=$ yellow, $180^{\circ}=$ bluish-green, and $270^{\circ}=$ blue) and $\mathrm{L}$ as lightness $(0=$ black and $100=$ white $)$ (McGuire, 1992).

Preparation of samples for $O A$ and $U A$ analysis. From each group of 24 apples (first group at harvest, second group after RA storage, third group after CA storage), the apples were divided into four replicates per block, giving totally 12 replicates per sample ( 24 apples: 3 blocks $\times 4$ replicates within each block $=12$ replicates totally). Each apple was cut into 12 pieces and peeled carefully using a peeler. Each piece of peel was punched into 9-mm disks and 36 disks were collected for each replicate. Disks were stored in $-20{ }^{\circ} \mathrm{C}$ until analysis. For OA and UA extraction, disks were dried in a freeze dryer for $24 \mathrm{~h}$. Lyophilized disks were extracted with $8 \mathrm{~mL}$ ethanol for $1.5 \mathrm{~h}$ in an ultrasonic bath at room temperature. Thereafter, the extract solution was centrifuged at $18,000 g_{\mathrm{n}}$ for $12 \mathrm{~min}$. A 7000 HPLC system (Merck-Hitachi, Darmstadt, Germany) with an ultraviolet detector was used to separate and quantify OA and UA at $207 \mathrm{~nm}$. A VYDAC column (Reverse Phase C18, CRT201 TP54; The Nest Group, Inc., Southborough, MA) was used for analysis with the mobile phase, methanol: acetonitrile: $\mathrm{H}_{2} \mathrm{O}(40: 40: 20, \mathrm{v} / \mathrm{v} / \mathrm{v})$, with isocratic flow, at $1.5 \mathrm{~mL} \cdot \mathrm{min}^{-1}$ flow rate, and the injection volume was $10 \mu \mathrm{L}$. External standards OA and UA were purchased (Extrasynthese, Genay Cedex, France) and were used for the construction of a standard curve. OA and UA in the samples were identified by comparing retention times and spectra with the external $\mathrm{OA}$ and UA standards. The quantification of $\mathrm{OA}$ and UA concentrations in the samples was performed by calculation, comparing with the standard curve.

TSS, $p H$, and TA. From the apple flesh, 11 g juice was collected using a Waring blender
(Model 91-358, New Hartford, CT). Juice was centrifuged for $10 \mathrm{~min}$ at $5500 \mathrm{~g}_{\mathrm{n}}$ and $2 \mathrm{~mL}$ supernatant was collected. The supernatant was mixed with $12 \mathrm{~mL} \mathrm{H}_{2} \mathrm{O}$ and titrated with $50 \mathrm{~mm} \mathrm{NaOH}$ to endpoint $\mathrm{pH} 8.3$ by using Titroline easy (SI Analytics $\mathrm{GmbH}$, Mainz, Germany). TA values were presented as percentage malic acid $(\mathrm{g} / 100 \mathrm{~mL})$. TSS values were measured by thermostatic refractometer RFM 80 (Bellingham + Stanley Ltd, Tunbridge Wells, UK) and presented as percentage of sugar $(\mathrm{g} / 100 \mathrm{~mL})$.

Statistics. All statistics were performed by using Minitab 16.2.4.0 (Minitab Ltd., State College, PA). Data were presented as means \pm SE of 12 independent replicates. Data were analyzed by general linear model to test the factor interaction, and statistical significance was considered at $P<0.05$ by using Tukey's test. Evaluation of the year-to-year effect on fruit quality parameters for each rootstock was performed by analysis of variance.

\section{Results}

Rootstock effect on $O A$ and UA concentrations at harvest time. Rootstocks affected OA and UA concentrations at different harvest times to different extent. At the first harvest in 2012, OA and UA in rootstock 'MM.106' were 61.9 and $416.3 \mu \mathrm{g} \cdot \mathrm{cm}^{-2}$, respectively, which were significantly higher than the concentrations in 'M.9' apples with 57.8 and $373.1 \mu \mathrm{g} \cdot \mathrm{cm}^{-2}$, respectively. At the second harvest in 2013, OA and UA levels in rootstock 'MM.106' apples were 53.3 and $327.4 \mu \mathrm{g} \cdot \mathrm{cm}^{-2}$, respectively, and they were significantly higher than the levels 48.8 and $296.5 \mu \mathrm{g} \cdot \mathrm{cm}^{-2}$ found in 'M.9' apples (Table 1). The same trend was also found for OA and UA concentrations at the third harvest time in both 2012 and 2013. At the rest of the harvest times, no significant differences were found between o rootstocks in the OA and UA concentrations. At harvest time in 2012, the highest concentrations of OA and UA in 'MM.106' rootstock apples were 63.4 and $416.3 \mu \mathrm{g} \cdot \mathrm{cm}^{-2}$, respectively, while they were 59.7 and $380.9 \mu \mathrm{g} \cdot \mathrm{cm}^{-2}$, respectively, in 'M.9' rootstock apples. On average, both $\mathrm{OA}$ and UA concentrations were higher in 2012 than in 2013. The highest OA concentration in 2013 was $53.8 \mu \mathrm{g} \cdot \mathrm{cm}^{-2}$, which was $15.1 \%$ lower than the highest OA concentration in 2012. The same trend was found for the highest UA concentration in 2013, which was $21.4 \%$ lower than the highest UA concentration in 2012 (Table 1).

Harvest time and storage effects on $O A$ and $U A$ concentrations. The three harvest times reflect different maturity of the apples. In general, the harvest time showed inconsistent effect for OA and UA concentrations under different conditions.

At harvest time in 2012, different harvest times had no significant effect on the OA and UA concentrations. The OA concentration ranged from 59.8 to $60.2 \mu \mathrm{g} \cdot \mathrm{cm}^{-2}$ and the UA concentration ranged from 385.9 to 394.7 $\mu \mathrm{g} \cdot \mathrm{cm}^{-2}$ (Table 2). After RA storage, fruit were harvested at the first and second harvest 
Table 1. Oleanolic acid (OA) and ursolic acid (UA) $\left(\mu \mathrm{g} \cdot \mathrm{cm}^{-2}\right)$ concentrations in peel of apple from rootstock 'MM.106' and 'M.9' at three harvest times in 2012 and 2013

\begin{tabular}{|c|c|c|c|c|c|c|c|}
\hline \multirow[b]{2}{*}{ Triterpenes } & \multirow[b]{2}{*}{ Rootstock } & \multicolumn{3}{|c|}{2012} & \multicolumn{3}{|c|}{2013} \\
\hline & & First harvest & Second harvest & Third harvest & First harvest & Second harvest & Third harvest \\
\hline \multirow[t]{2}{*}{$\overline{\mathrm{OA}}$} & 'MM.106' & $61.9 \pm 0.9 a^{z} \alpha^{y}$ & $60.7 \pm 1.1 \mathrm{a} \alpha$ & $63.4 \pm 0.5$ a $\alpha$ & $52.6 \pm 0.7 \mathrm{a} \alpha$ & $53.3 \pm 0.8$ a $\alpha$ & $52.3 \pm 0.8$ a $\alpha$ \\
\hline & 'M.9' & $57.8 \pm 1.0 \mathrm{~b} \alpha$ & $59.7 \pm 1.3$ a $\alpha$ & $56.9 \pm 1.0 \mathrm{~b} \alpha$ & $53.8 \pm 1.4$ a $\alpha$ & $48.8 \pm 0.7 \mathrm{~b} \beta$ & $47.0 \pm 0.6 \mathrm{~b} \beta$ \\
\hline \multirow[t]{2}{*}{ UA } & 'MM.106' & $416.3 \pm 5.3$ a $\alpha$ & $390.9 \pm 4.7$ a $\alpha$ & $415.0 \pm 3.5$ a $\alpha$ & $325.4 \pm 4.6$ a $\alpha$ & $327.4 \pm 4.6$ a $\alpha$ & $326.5 \pm 4.5$ a $\alpha$ \\
\hline & 'M.9' & $373.1 \pm 6.2 \mathrm{~b} \alpha$ & $380.9 \pm 6.6$ a $\alpha$ & $364.2 \pm 4.9 \mathrm{~b} \alpha$ & $319.7 \pm 5.0 \mathrm{a} \alpha$ & $296.5 \pm 3.5$ b $\beta$ & $290.5 \pm 3.5 \mathrm{~b} \beta$ \\
\hline
\end{tabular}

${ }^{\mathrm{z}}$ Different letters indicate significant differences between the two rootstocks at the same harvest times by Tukey test $(P<0.05)$.

${ }^{y}$ Different letters indicate significant differences between harvest times with the same rootstock by Tukey test $(P<0.05)$.

Table 2. Oleanolic acid (OA) and ursolic acid (UA) $\left(\mu \mathrm{g} \cdot \mathrm{cm}^{-2}\right)$ concentrations in apple peel at harvest time, after regular atmospheric (RA) storage, and controlled atmospheric (CA) storage in 2012 and 2013.

\begin{tabular}{|c|c|c|c|c|c|}
\hline \multirow[b]{2}{*}{ Harvest time } & \multirow[b]{2}{*}{ Harvest/storage } & \multicolumn{2}{|c|}{2012} & \multicolumn{2}{|c|}{2013} \\
\hline & & $\mathrm{OA}$ & UA & $\mathrm{OA}$ & UA \\
\hline \multirow[t]{3}{*}{ First harvest } & At harvest & $59.8 \pm 0.8 \mathrm{a}^{\mathrm{z}} \alpha^{\mathrm{y}}$ & $394.7 \pm 6.0$ a $\alpha$ & $53.2 \pm 0.8$ a $\alpha$ & $322.5 \pm 3.4$ a $\alpha$ \\
\hline & RA storage & $59.1 \pm 0.7$ a $\alpha$ & $400.3 \pm 5.0$ a $\alpha$ & $51.7 \pm 0.5$ a $\alpha$ & $323.8 \pm 2.7$ a $\alpha$ \\
\hline & CA storage & $58.7 \pm 0.6$ a $\beta$ & $390.1 \pm 3.8$ a $\alpha$ & $48.3 \pm 0.8 \mathrm{~b} \beta$ & $318.0 \pm 4.0 \mathrm{a} \alpha$ \\
\hline \multirow[t]{3}{*}{ Second harvest } & At harvest & $60.2 \pm 0.8$ a $\alpha$ & $385.9 \pm 4.1 \mathrm{~b} \alpha$ & $51.1 \pm 0.7$ a $\alpha \beta$ & $311.9 \pm 4.3$ a $\alpha$ \\
\hline & RA storage & $60.9 \pm 0.7$ a $\alpha$ & $402.0 \pm 3.4$ a $\alpha$ & $48.4 \pm 0.7 \mathrm{~b} \beta$ & $309.0 \pm 4.0 \mathrm{a} \beta$ \\
\hline & CA storage & $61.7 \pm 0.6 \mathrm{a} \alpha$ & $393.2 \pm 2.9 \mathrm{ab} \alpha$ & $48.0 \pm 0.5 \mathrm{~b} \beta$ & $311.1 \pm 3.4 \mathrm{a} \alpha$ \\
\hline \multirow[t]{3}{*}{ Third harvest } & At harvest & $60.2 \pm 0.9$ a $\alpha$ & $389.6 \pm 6.1$ a $\alpha$ & $49.7 \pm 0.7$ a $\beta$ & $308.5 \pm 3.4$ a $\alpha$ \\
\hline & RA storage & $56.3 \pm 0.8 \mathrm{~b} \beta$ & $380.6 \pm 5.4$ a $\beta$ & $52.0 \pm 1.0$ a $\alpha$ & $314.0 \pm 3.9$ a $\alpha \beta$ \\
\hline & CA storage & $60.4 \pm 0.6$ a $\alpha \beta$ & $390.8 \pm 3.5$ a $\alpha$ & $51.2 \pm 0.9$ a $\alpha$ & $313.0 \pm 4.6$ a $\alpha$ \\
\hline
\end{tabular}

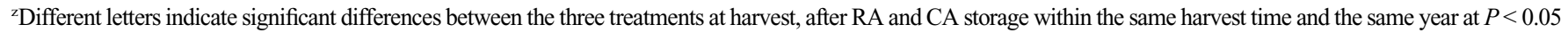
by Tukey test.

${ }^{y}$ Different letters indicate significant differences between different harvest times within the same harvest or storage conditions and the same year at $P<0.05$ by Tukey test.

times showed higher OA and UA concentrations than fruit harvested at the third harvest time, while highest OA and UA concentrations were 60.9 and $402.0 \mu \mathrm{g} \cdot \mathrm{cm}^{-2}$, respectively, in fruit of the second harvest time. After CA storage, a similar trend was observed that the highest OA and UA concentrations were found in the fruit of second harvest time, but no significant difference was found for UA concentration in fruit at different harvest times (Table 2).

At harvest time in 2013, the highest OA concentration $\left(53.2 \mu \mathrm{g} \cdot \mathrm{cm}^{-2}\right)$ was found in fruit at the first harvest time, but no differences were found on UA concentration in fruit at different harvest times, with concentrations ranging from 308.5 to $322.5 \mu \mathrm{g} \cdot \mathrm{cm}^{-2}$ (Table 2). After RA storage, OA concentration in fruit of the first and third harvest time showed higher value, 51.7 and $52.0 \mu \mathrm{g} \cdot \mathrm{cm}^{-2}$, respectively, than that of the second harvest time with $48.4 \mu \mathrm{g} \cdot \mathrm{cm}^{-2}$; UA concentration in fruit of the first harvest time showed the highest value with $323.8 \mu \mathrm{g} \cdot \mathrm{cm}^{-2}$. After CA storage, the highest OA concentration, 51.2 $\mu \mathrm{g} \cdot \mathrm{cm}^{-2}$, was found in fruit at the third harvest time, and it was significantly higher than the values at the first and second harvest time, while no differences were found for UA concentration in fruit at the different harvest times (Table 2).

Neither RA storage nor CA storage did result in any difference in UA concentrations in any of the investigated years, but some differences were found for OA concentration (Table 2). In 2012, CA storage resulted in higher OA concentration $\left(60.4 \mu \mathrm{g} \cdot \mathrm{cm}^{-2}\right)$ than RA storage $\left(56.3 \mu \mathrm{g} \cdot \mathrm{cm}^{-2}\right)$ in fruit at the third harvest time; in 2013, RA storage resulted in higher OA concentration $\left(51.7 \mu \mathrm{g} \cdot \mathrm{cm}^{-2}\right)$ than CA storage $\left(48.3 \mu \mathrm{g} \cdot \mathrm{cm}^{-2}\right)$ in fruit at the first harvest time. For OA concentration at the other cases in both years, no differences were found between RA storage and CA storage.

When comparing OA and UA concentrations in fruit at harvest time and after storage, a year-to-year difference was observed. For OA concentration in fruit in 2012 , the value of the third harvest time after RA storage decreased by $6.5 \%$ as compared with the initial value of $60.2 \mu \mathrm{g} \cdot \mathrm{cm}^{-2}$ at harvest time, while no differences were found between OA concentration at harvest time and after storage at the first and second harvest times (Table 2). For OA concentration in fruit in 2013, the value in fruit at the first harvest time after CA storage decreased by $9.2 \%$ as compared with that at harvest time with $53.2 \mu \mathrm{g} \cdot \mathrm{cm}^{-2}$. A similar trend was found in fruit at the second harvest time, where both RA and CA storage apples showed reduced $\mathrm{OA}$ concentration by $5.3 \%$ and $6.1 \%$ as compared with $51.1 \mu \mathrm{g} \cdot \mathrm{cm}^{-2}$ at harvest time. For UA concentration, the only difference between the value at harvest time and after storage was found in fruit at the second harvest time in 2012, where the UA concentration after RA storage increased by $4.3 \%$ as compared with that $385.9 \mu \mathrm{g} \cdot \mathrm{cm}^{-2}$ at harvest time (Table 2).

TSS and TA. Different harvest times showed different effects on TSS of 'M.9' and 'MM.106' apples. At harvest time in 'M.9' apples, the highest TSS was $12.36 \%$, which was found at the second harvest time in 2012 , and $11.86 \%$ at the third harvest time in 2013, and the same trend was found after RA and CA storage (Table 3). Both at harvest time and after RA storage in 'MM.106', the third harvest time in 2012 and the second harvest time in 2013 showed highest TSS concentration (Table 3). The rootstock did not result in any clear tendency for TSS concentration (Table 3).
In general, the TA showed a decreasing trend from the first harvest to the third harvest time at harvest or after storage, although the differences were not always significant (Table 3 ). When the different rootstocks were compared, at harvest time, 'MM.106' apples showed higher TA concentration than 'M.9' apples in 2013, but the same trend was only found at the second harvest time in 2012 . After RA and CA storage in 2012, 'MM.106' apples had higher TA concentration $(0.69 \%$ and $0.83 \%)$ than 'M.9' apples $(0.60 \%$ and $0.71 \%$ ) at the third harvest time, and the same trend was found in 2013 (Table 3).

Fruit color. The hue angle of the sunny side was significantly smaller than that of the shaded side, which indicated that the sunny side was significantly redder than the shaded side (Table 4). At harvest time of 2012, the hue angle of the sunny side showed no difference between the three harvest times in 'M.9' apples, but on the shaded side, the third harvest time apples showed the smallest hue angle. For 'MM.106' apples at harvest time, lower values for hue angle were found for both the sunny and shaded side for the third harvest time, as compared with the first two harvest times. After RA storage and CA storage of 2012, the third harvest time of 'M.9' and 'MM.106' apples showed the lowest hue angle for both the sunny and shaded side, and similar tendency was found in 2013, though the third harvest values were not always significantly different from the second harvest (Table 4).

The two different rootstocks resulted only in slight differences concerning fruit color (Table 4). In 2012, the hue angle of 'M.9' apples' shaded side was larger than 'MM.106' apples at the third harvest time, both at harvest time and after RA storage, and the same tendency was found on the sunny 
side of the third harvest time apples after CA storage. In 2013, the hue angle of 'MM.106' apples' sunny side at harvest time was larger than 'M.9' apples at the first and second harvest occasions, while no difference was found between the rootstocks after storage (Table 4).

Comparing the RA storage and CA storage, there was no difference in the hue angle, except for the third harvest time apples in 2012, where the RA stored 'M.9' apples had a significantly larger hue angle than the CA stored 'M.9' apples (Table 4, significances are not shown).

Correlation. Pearson correlation was used to express the relation of pairs of variables among triterpene concentration and fruit quality indexes. OA concentration was positively correlated with UA concentration both at harvest time $(r=0.917 ; P=0.000)$, after RA storage $(r=0.908 ; P=0.000)$, and after CA storage $(r=0.950 ; P=0.000)$ (Table 4). $\mathrm{OA}$ and UA concentrations were positively correlated with TA and TSS, and also with the color hue angle. OA and UA concentrations did not show any significant correlation with $\mathrm{pH}$ at harvest time, but after $\mathrm{RA}$ and $\mathrm{CA}$ storage, both OA and UA were positively correlated with $\mathrm{pH}$ (Table 5).

The year-to-year influence. The year-toyear influence was found to be significant for the OA and UA concentrations, fruit color, $\mathrm{TA}$, and $\mathrm{pH}$, with some exceptions. Year did not show significant effect on OA concentration at the third harvest time in 'MM.106' apples after cold storage (Table 6). It also did not show any significant effect on $\mathrm{pH}$ at harvest for the third harvest time in

Table 3. Total soluble solids (TSS) and titratable acidity (TA) of apple fruit of three harvest times directly at harvest, after regular atmospheric (RA) storage, and after controlled atmospheric (CA) storage in 2012 and 2013.

\begin{tabular}{|c|c|c|c|c|c|}
\hline \multirow[b]{3}{*}{ Harvest/storage } & \multirow[b]{3}{*}{ Harvest times } & \multicolumn{4}{|c|}{ TSS (\%) } \\
\hline & & \multicolumn{2}{|c|}{2012} & \multicolumn{2}{|c|}{2013} \\
\hline & & 'MM.106' & 'M.9' & 'MM.106' & 'M.9' \\
\hline \multirow[t]{3}{*}{ At harvest time } & First & $11.68 b^{z} \alpha^{y}$ & $11.48 \mathrm{~b} \alpha$ & $11.78 \mathrm{ab} \alpha$ & $10.91 \mathrm{~b} \beta$ \\
\hline & Second & $11.73 \mathrm{~b} \beta$ & 12.36 a $\alpha$ & 12.03 a $\alpha$ & $11.16 \mathrm{~b} \beta$ \\
\hline & Third & 12.64 a $\alpha$ & $11.46 \mathrm{~b} \beta$ & $11.24 \mathrm{~b} \beta$ & $11.86 \mathrm{a} \alpha$ \\
\hline \multirow[t]{3}{*}{ After RA storage } & First & $12.83 \mathrm{ab} \alpha$ & 12.53 a $\alpha$ & $12.55 \mathrm{a} \alpha$ & $11.97 \mathrm{ab} \beta$ \\
\hline & Second & $12.48 \mathrm{~b} \alpha$ & $12.54 \mathrm{a} \alpha$ & $12.61 \mathrm{a} \alpha$ & $11.63 \mathrm{~b} \beta$ \\
\hline & Third & 13.60 a $\alpha$ & $11.73 \mathrm{~b} \beta$ & $11.20 \mathrm{~b} \beta$ & 12.39 a $\alpha$ \\
\hline \multirow[t]{6}{*}{ After CA storage } & First & $12.63 \mathrm{~b} \alpha$ & $12.83 \mathrm{~b} \alpha$ & $13.23 \mathrm{a} \alpha$ & $11.90 \mathrm{ab} \beta$ \\
\hline & Second & $12.41 \mathrm{~b} \beta$ & 13.69 a $\alpha$ & 12.83 a $\alpha$ & $11.59 \mathrm{~b} \beta$ \\
\hline & Third & 14.62 a $\alpha$ & $12.10 \mathrm{~b} \beta$ & $11.82 \mathrm{~b} \beta$ & 12.24 a $\alpha$ \\
\hline & & \multicolumn{4}{|c|}{ TA $(\%)$} \\
\hline & & \multicolumn{2}{|c|}{2012} & \multicolumn{2}{|c|}{2013} \\
\hline & & 'MM.106' & 'M.9' & 'MM.106' & 'M.9' \\
\hline \multirow[t]{3}{*}{ At harvest time } & First & $1.06 \mathrm{a}^{\mathrm{z}} \alpha^{\mathrm{y}}$ & $1.02 \mathrm{a} \alpha$ & 0.97 a $\alpha$ & 0.88 a $\beta$ \\
\hline & Second & $1.07 \mathrm{a} \alpha$ & 0.98 a $\beta$ & $0.86 \mathrm{~b} \alpha$ & $0.79 \mathrm{~b} \beta$ \\
\hline & Third & $1.02 \mathrm{a} \alpha$ & 0.97 a $\alpha$ & $0.89 \mathrm{~b} \alpha$ & $0.79 \mathrm{~b} \beta$ \\
\hline \multirow[t]{3}{*}{ After RA storage } & First & 0.76 a $\beta$ & 0.82 a $\alpha$ & 0.64 a $\alpha$ & 0.64 a $\alpha$ \\
\hline & Second & $0.67 \mathrm{~b} \alpha$ & $0.62 \mathrm{~b} \alpha$ & 0.63 a $\alpha$ & 0.62 a $\alpha$ \\
\hline & Third & $0.69 \mathrm{~b} \alpha$ & $0.60 \mathrm{~b} \beta$ & 0.63 a $\alpha$ & $0.56 \mathrm{~b} \beta$ \\
\hline \multirow[t]{3}{*}{ After CA storage } & First & 0.86 a $\beta$ & 0.99 a $\alpha$ & 0.76 a $\alpha$ & 0.68 a $\beta$ \\
\hline & Second & $0.89 \mathrm{ab} \alpha$ & $0.86 \mathrm{~b} \alpha$ & $0.74 \mathrm{ab} \alpha$ & 0.72 a $\alpha$ \\
\hline & Third & $0.83 \mathrm{~b} \alpha$ & 0.71 с $\beta$ & $0.69 \mathrm{~b} \alpha$ & $0.61 \mathrm{~b} \beta$ \\
\hline
\end{tabular}

${ }^{\mathrm{z}}$ Different letters indicate significant differences between three harvest times within the same treatment (harvest/storage type) and the same year at $P<0.05$ by Turkey test.

${ }^{y}$ Different letters indicate significant differences between two rootstocks within the same treatment (harvest/storage type) and the same year at $P<0.05$ by Tukey test.
'MM.106' apples and for the second harvest time in 'M.9' apples (Table 6). The year-toyear influence on hue angle of the 'M.9' apples was stronger than the influence on 'MM.106' apples. For the TSS, the year difference was significantly different in four cases of nine in 'MM.106' apples and seven cases of nine in 'M.9' apples (Table 6).

\section{Discussion}

Rootstock has been used for modifying the growth of deciduous fruit trees for a long time. Rootstocks can influence scion vigor, cropping, fruit quality, climatic adaptability, and susceptibility to pests and diseases (Ferree and Warrington, 2003; Webster, 1995). The results of this investigation showed that rootstock was the factor which gave the most consistent changes in the concentration of $\mathrm{UA}$ and $\mathrm{OA}$ of the investigated factors. In four of six harvest times (three per year), 'MM.106' gave higher UA and OA concentration than 'M.9'. A previous investigation of 'Pink Lady' apples on 'MM.106' and 'M.9' rootstocks showed differences in $g_{\mathrm{S}}$, number of fruit, fresh weight of fruit, flesh firmness, and acidity between the two rootstocks (Talluto et al., 2008). Since the rootstock 'MM.106' has been described as semidwarfing while 'M.9' is described as dwarfing, different growth patterns impact hormones metabolism and translocation, supply of minerals and water, as well as light interception and photosynthesis production and thereby the size, quality, and anatomy of fruit and leaves (Gheyas et al., 1996; Tromp et al., 2005). However, the dwarfing growth of the rootstock is probably the effect of a range of complex interactions between different features and resulting in differences in multiple quality traits. Two rootstocks used in this investigation have been described as having different sensitivities to plant pathogens. 'M.9' has been described as susceptible to fire blight and woolly aphid, and 'MM.106' has been described as intermediate resistant to fire bright and resistant to woolly aphid, respectively (Rom and Carlson, 1987). Triterpenoids, and in some cases specifically OA or UA, have been linked to insecticidal and antifungal properties. Neem (Azadirachta

Table 4. Fruit color on the sunny and shadow side of apple peel expressed as hue angle $\left(\mathrm{h}^{\circ}\right)$ at harvest time, after regular atmospheric (RA) storage, and after controlled atmospheric (CA) storage in 2012 and 2013.

\begin{tabular}{|c|c|c|c|c|c|c|c|c|c|}
\hline \multirow[b]{3}{*}{ Harvest/storage } & \multirow[b]{3}{*}{ Harvest times } & \multicolumn{8}{|c|}{ Hue angle $\left(^{\circ}\right)$} \\
\hline & & \multicolumn{4}{|c|}{2012} & \multicolumn{4}{|c|}{2013} \\
\hline & & 'MM.106' & 'M.9' & 'MM.106' & 'M.9' & 'MM.106' & 'M.9' & 'MM.106' & 'M.9' \\
\hline \multirow{2}{*}{ At harvest time } & Second & 47.4 a $\alpha$ & 44.8 a $\alpha$ & 106.4 a $\alpha$ & $100.8 \mathrm{ab} \alpha$ & $30.3 \mathrm{~b} \alpha$ & $24.9 \mathrm{~b} \beta$ & $66.1 \mathrm{~b} \alpha$ & $68.5 \mathrm{~b} \alpha$ \\
\hline & Third & $30.5 \mathrm{~b} \alpha$ & $41.1 \mathrm{a} \alpha$ & $67.2 \mathrm{~b} \beta$ & $93.7 \mathrm{~b} \alpha$ & $26.5 \mathrm{~b} \alpha$ & $23.2 \mathrm{~b} \alpha$ & $55.4 \mathrm{~b} \alpha$ & $58.1 \mathrm{c} \alpha$ \\
\hline \multirow[t]{2}{*}{ After RA storage } & First & 49.9 а $\alpha$ & 55.8 a $\alpha$ & $91.2 \mathrm{a} \alpha$ & 98.4 a $\alpha$ & 27.5 a $\alpha$ & 35.9 a $\alpha$ & 78.3 a $\alpha$ & 74.5 a $\alpha$ \\
\hline & Second & 50.2 a $\alpha$ & $54.1 \mathrm{a} \alpha$ & 93.8 a $\alpha$ & $90.6 \mathrm{~b} \alpha$ & $30.5 \mathrm{~b} \alpha$ & $25.4 \mathrm{~b} \alpha$ & $69.9 \mathrm{ab} \alpha$ & 74.0 a $\alpha$ \\
\hline \multirow{2}{*}{ After CA storage } & Second & 52.6 a $\alpha$ & 56.6 a $\alpha$ & 94.0 a $\alpha$ & 98.1 a $\alpha$ & $31.1 \mathrm{~b} \alpha$ & $27.7 \mathrm{~b} \alpha$ & $71.0 \mathrm{~b} \alpha$ & 71.5 a $\alpha$ \\
\hline & Third & $24.4 \mathrm{~b} \beta$ & $29.2 \mathrm{~b} \alpha$ & $63.2 \mathrm{~b} \alpha$ & $68.8 \mathrm{~b} \alpha$ & $22.9 \mathrm{c} \alpha$ & $24.3 \mathrm{~b} \alpha$ & $63.8 \mathrm{~b} \alpha$ & $59.9 \mathrm{~b} \alpha$ \\
\hline
\end{tabular}

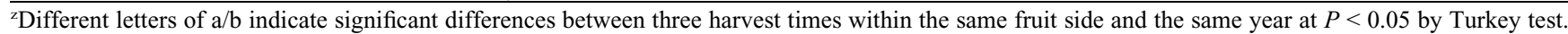

${ }^{y}$ Different letters of $\mathrm{a} / \mathrm{b}$ indicate significant differences between two rootstocks within the same fruit side and the same year at $P<0.05$ by Tukey test. 
Table 5. Pearson correlation between oleanolic acid (OA) and ursolic acid (UA) and fruit quality at harvest time, after regular atmospheric (RA) storage, and after controlled atmospheric (CA) storage.

\begin{tabular}{lccccccc}
\hline & Harvest/storage & UA & TA & TSS & pH & Hue-S & Hue-Sh \\
\hline OA & At harvest time & $0.917^{* * *}$ & $0.638^{* * *}$ & $0.374^{* * *}$ & -0.111 & $0.344^{* * *}$ & $0.454^{* * *}$ \\
UA & & & $0.711^{* * *}$ & $0.343^{* * *}$ & -0.135 & $0.339^{* * *}$ & $0.489^{* * *}$ \\
OA & After RA storage & $0.908^{* * *}$ & $0.401^{* * *}$ & $0.388^{* * *}$ & $0.606^{* * *}$ & $0.502^{* * *}$ & $0.396^{* * *}$ \\
UA & & & $0.401^{* * *}$ & $0.441^{* * *}$ & $0.756^{* * *}$ & $0.612^{* * *}$ & $0.503^{* * *}$ \\
OA & After CA storage & $0.950^{* * *}$ & $0.539^{* * *}$ & $0.361^{* * *}$ & $0.633^{* * *}$ & $0.432^{* * *}$ & $0.283^{* *}$ \\
UA & & & $0.615^{* * *}$ & $0.366^{* * *}$ & $0.744^{* * *}$ & $0.508^{* * *}$ & $0.389^{* * *}$ \\
\hline
\end{tabular}

$\mathrm{TA}=$ titratable acidity; TSS $=$ total soluble solids; Hue-S $=$ Hue angle on sunny side; Hue-Sh $=$ Hue angle on shadow side.

Table 6. Differences between years shown by $P$ value of one-way analysis of variance for each parameter of two rootstocks.

\begin{tabular}{|c|c|c|c|c|c|c|c|c|c|}
\hline \multirow[b]{3}{*}{ Parameters } & \multicolumn{9}{|c|}{ 'MM.106' } \\
\hline & \multicolumn{3}{|c|}{ At harvest time } & \multicolumn{3}{|c|}{ After cold storage } & \multicolumn{3}{|c|}{ After ULO storage } \\
\hline & First & Second & Third & First & Second & Third & First & Second & Third \\
\hline$\overline{\mathrm{OA}}$ & 0.000 & 0.000 & 0.000 & 0.000 & 0.000 & 0.072 & 0.000 & 0.000 & 0.000 \\
\hline UA & 0.000 & 0.000 & 0.000 & 0.000 & 0.000 & 0.000 & 0.000 & 0.000 & 0.000 \\
\hline Hue-S & 0.039 & 0.000 & 0.340 & 0.019 & 0.000 & 0.004 & 0.023 & 0.000 & 0.348 \\
\hline Hue-Sh & 0.017 & 0.000 & 0.058 & 0.030 & 0.000 & 0.269 & 0.068 & 0.000 & 0.906 \\
\hline TSS & 0.703 & 0.212 & 0.000 & 0.076 & 0.684 & 0.000 & 0.020 & 0.145 & 0.000 \\
\hline TA & 0.001 & 0.000 & 0.000 & 0.000 & 0.050 & 0.010 & 0.000 & 0.000 & 0.000 \\
\hline \multirow[t]{4}{*}{$\mathrm{pH}$} & 0.000 & 0.036 & 0.782 & 0.000 & 0.000 & 0.000 & 0.000 & 0.019 & 0.000 \\
\hline & \multicolumn{9}{|c|}{ 'M.9' } \\
\hline & \multicolumn{3}{|c|}{ At harvest time } & \multicolumn{3}{|c|}{ After cold storage } & \multicolumn{3}{|c|}{ After ULO storage } \\
\hline & First & Second & Third & First & Second & Third & First & Second & Third \\
\hline$\overline{\mathrm{OA}}$ & 0.027 & 0.000 & 0.000 & 0.001 & 0.000 & 0.003 & 0.000 & 0.000 & 0.000 \\
\hline UA & 0.000 & 0.000 & 0.000 & 0.000 & 0.000 & 0.000 & 0.000 & 0.000 & 0.000 \\
\hline Hue-S & 0.039 & 0.105 & 0.000 & 0.000 & 0.000 & 0.000 & 0.000 & 0.000 & 0.011 \\
\hline Hue-Sh & 0.000 & 0.000 & 0.000 & 0.000 & 0.000 & 0.000 & 0.005 & 0.000 & 0.022 \\
\hline TSS & 0.017 & 0.000 & 0.065 & 0.042 & 0.002 & 0.012 & 0.005 & 0.000 & 0.554 \\
\hline TA & 0.000 & 0.000 & 0.000 & 0.000 & 0.956 & 0.036 & 0.000 & 0.000 & 0.000 \\
\hline $\mathrm{pH}$ & 0.013 & 0.947 & 0.000 & 0.000 & 0.000 & 0.000 & 0.000 & 0.000 & 0.000 \\
\hline
\end{tabular}

$\mathrm{OA}=$ oleanolic acid; $\mathrm{UA}=$ ursolic acid; Hue-S = hue angle on sunny side; Hue-Sh = hue angle on shadow side; $\mathrm{TSS}=$ total soluble solids; TA $=$ titratable acidity; $\mathrm{ULO}=$ ultra-low oxygen .

indica) as an insecticide contains a range of different triterpenoids. In commercial products, the active ingredient azadirachtin is used (Nisbet, 2000; Salehzadeh et al., 2002). UA isolated from Breonadia salicina was found to have antifungal activity against six investigated plant pathogenic fungi, though the minimum inhibitory concentration values varied (Mahlo et al., 2013). OA was found to have the highest antifungal activity against Aspergillus, Candida, and Penicillium sp., when several different compounds were isolated from Ficus drupacea (Yessoufou et al., 2015). Therefore, the higher concentration of OA and UA found in 'MM.106' in this investigation could possibly be linked to the previously described higher resistance to plant pathogens in the 'MM.106' rootstock than in 'M.9'.

Previous investigations have shown that rootstock can also influence the acidity of fruit. The fruit from trees with the rootstock of sour orange in 'Valencia' orange had higher TSS and TA (Economides, 1977), and the same result was found on 'Lapithkiotiki' lemon (Georgiou, 2009). A study on 'Delicious' apple showed that fruit from trees on 'M.27 EMLA' or 'M.9' had significantly higher TSS than fruit from trees on 'M.7 EMLA', 'MAC 9', or 'OAR 1', but this result was only shown in one of the investigated years (Autio, 1991). In the present study, the harvest maturity can influence fruit quality and phytochemical concentration. Studies on apples have found that early harvested fruit had higher firmness (Bulens et al., 2012; Kweon et al., 2013), and also higher TA, but lower TSS (Kweon et al., 2013). In accordance with this, in the present study at harvest in year 2012, and most often after RA or CA storage in both years, the fruit of the first or second harvest time had higher TA concentration, whereas the fruit of the second or third harvest time had higher TSS as compared with the first harvest time fruit at harvest. A previous study on the cuticular wax of 'Delicious' apple showed that the hydrocarbons and diols (more than half was UA) increased significantly during fruit development (Ju and Bramlage, 2001), but the wax compounds were detected just once per month from June to September, and the large increase of UA was found between August and September. Another study on apple showed that wax composition did not change much with different picking date (Veraverbeke et al., 2001). In our study, 'Aroma' apples, which were collected every week during the fruit ripening in September, showed inconsistent UA concentration of fruit of both rootstocks 'M.9' and 'MM.106' with different harvest times. At harvest, the first harvest time apples showed higher UA concentration than that at the second harvest time, but the third harvest time 'MM.106' apples also showed higher UA concentration. This result indicates that UA concentration could remain stable to some extent during the fruit maturation.

Effects of the two main storage methods, RA storage and CA storage, on fruit quality, including antioxidant concentration, have been widely studied. Some previous studies have confirmed that the triterpene concentration in apple fruit can show variability for different cultivars and also for different investigated seasons (Lv et al., 2015a; Morice et al., 1973). For example, a study on the surface wax composition of apple fruits showed that the petroleum ether-insoluble acids (PEIA; which were mainly UA according to the author) in three cultivars (Dougherty, Granny Smith, and Sturmer) reacted differently in RA storage. The PEIA in 'Dougherty' and 'Granny Smith' showed stable concentration or increased after 70-d RA storage; while for 'Sturmer', the PEIA decreased in the first investigated year and maintained relative stable in the second investigated year (Morice et al., 1973). Our previous study also showed that UA concentration in 'Gloster' remained stable after cold storage, while OA and UA concentrations in 'Aroma' were unchanged in one investigated year, but changed in the other investigated year (Lv et al., 2015a). In our present study, no difference was found between RA and CA storage in the UA concentration in any of the investigated years; while the OA concentration showed different response to RA and CA storage in the two investigated years. After RA and CA storage, some decreased values were found for OA concentration as 
compared with the value at harvest time. The postharvest changes of most wax components have been found to be associated with ethylene production and ripening (Dong et al., 2012), though in this investigation the storage methods seemed to have quite small influence on maturation processes that affected the UA concentration, but some influence was observed for OA concentration.

Year-to-year variations in the climate are known to influence different quality traits. For example, in apple, TSS, TA, flesh firmness, and color have been found to vary between years (Robinson et al., 1991; Rutkowski et al., 2005). In this investigation, higher average concentrations of OA and UA as well as higher levels of TA were found in 2012 but not in 2013, while the hue angle showed that the apples were redder (lower values of hue angle) in 2013 than in 2012. These recorded differences between years might indicate different climate conditions and cultivation effects between the 2 years and could explain the different pattern in $\mathrm{OA}$ and UA levels during the ripening period, as registered at the three harvest times. Strong and complex interaction between rootstock and climatic conditions and also the year-toyear variations have been reported for Japanese plum quality (Daza et al., 2008). The present result also confirmed the effect of complex interaction for rootstock/storage method and harvest time/storage method on triterpenes concentration in apple peel.

\section{Conclusions}

The results showed that in the investigated cultivar, the effects of the rootstock gave the largest and most consistent differences on the concentrations of the OA and UA, while storage and harvest time (reflecting ripening stage) gave minor and inconsistent changes. The rootstock 'MM.106' should be considered as a good resource if higher concentrations of triterpenes should be promoted as compared with rootstock 'M.9'. Different harvest time showed minor effect on $\mathrm{OA}$ and UA concentrations in 'MM.106' apples, while if 'M.9' apples are consumed directly after harvest, the first harvest time gave higher OA and UA concentrations. Apples harvested at the second harvest time (commercial harvest) can keep stable or increased OA and UA concentrations after RA and CA storage as compared with the levels at harvest time. For the earlyor late-harvested apples, OA and UA concentrations in different rootstocks might show inconsistent changes after storage. In conclusion, previous results demonstrating major significant differences between three investigated apple cultivars in the concentration of UA and OA (Lv et al., 2015b), together with present results indicate that there is a potential to use the variability of scion/rootstock genotype combination. The relative stability in the concentration of UA and OA while subjected to changes in harvest time and environmental factors, during the two investigated years and different storage methods are also good prerequisites for successful breeding for increased levels of these desirable quality traits.

\section{Literature Cited}

Autio, W.R. 1991. Rootstock affects ripening and other qualities of 'Delicious' apples. J. Amer. Soc. Hort. Sci. 116:378-382.

Bulens, I., B. Van de Poel, M.L.A.T.M. Hertog, M. P. De Proft, A.H. Geeraerd, and B.M. Nicolai. 2012. Influence of harvest time and 1-MCP application on postharvest ripening and ethylene biosynthesis of 'Jonagold' apple. Postharvest Biol. Technol. 72:11-19.

Burda, S., W. Oleszek, and C.Y. Lee. 1990. Phenolic compounds and their changes in apples during maturation and cold storage. J. Agr. Food Chem. 38:945-948.

Castle, W.S. 1995. Rootstock as a fruit quality factor in citrus and deciduous tree crops. N.Z. J. Crop Hort. 23:383-394.

Cefarelli, G., B. D'Abrosca, A. Fiorentino, A. Izzo, C. Mastellone, S. Pacifico, and V. Piscopo. 2006. Free-radical-scavenging and antioxidant activities of secondary metabolites from reddened cv. Annurca apple fruits. J. Agr. Food Chem. 54:803-809.

Cohen, S. and A. Naor. 2002. The effect of three rootstocks on water use, canopy conductance and hydraulic parameters of apple trees and predicting canopy from hydraulic conductance. Plant Cell Environ. 25:17-28.

Cohen, S., A. Naor, J. Bennink, A. Grava, and M. Tyree. 2007. Hydraulic resistance components of mature apple trees on rootstocks of different vigours. J. Expt. Bot. 58:4213-4224.

Crosby, K., J. Jifon, L. Pike, and K.S. Yoo. 2007. Breeding vegetables for optimum levels of phytochemicals. Acta Hort. (ISHS) 744:219-224.

Davuluri, G.R., A. Van Tuinen, P.D. Fraser, A. Manfredonia, R. Newman, D. Burgess, D.A. Brummell, S.R. King, J. Palys, J. Uhlig, P.M. Bramley, H.M.J. Pennings, and C. Bowler. 2005. Fruit-specific RNAi-mediated suppression of DET1 enhances carotenoid and flavonoid concentration in tomatoes. Natl. Biotechnol. 23:890-895.

Daza, A., P.A. García-Galavís, M.J. Grande, and C. Santamaría. 2008. Fruit quality parameters of 'Pioneer' Japanese plums produced on eight different rootstocks. Sci. Hort. 118:206-211.

Dong, X., J. Rao, D. Huber, X. Chang, and F. Xin. 2012. Wax composition of 'Red Fuji' apple fruit during development and during storage after 1-methylcyclopropene treatment. Hort. Environ. Biotechnol. 53:288-297.

Dris, R.R.N. and E. Fallahi. 1999. Relationships between leaf and fruit minerals and fruit quality attributes of apples grown under northern conditions. J. Plant Nutr. 22:1839-1851.

Economides, C.V. 1977. The influence of rootstocks on tree growth, yield and fruit quality of valencia oranges in cyprus. J. Hort. Sci.

Ericsson, N.A. 1982. Influence of harvest time on yield, fruit growth and quality in three apple cultivars. SLU Rep. 23, 9-16.

Fallahi, E., I.-J. Chun, G.H. Neilsen, and W.M. Colt. 2001. Effects of three rootstocks on photosynthesis, leaf mineral nutrition, and vegetative growth of 'BC-2 Fuji' apple trees. J. Plant Nutr. 24:827-834.

Fallahi, E., W.M. Colt, B. Fallahi, and I. Chun. 2002. The importance of apple rootstocks on tree growth, yield, fruit quality, leaf nutrition and photosynthesis with an emphasis on 'Fuji'. HortTechnology 12:38-44.
Farneti, B., D. Masuero, F. Costa, P. Magnago, M. Malnoy, G. Costa, U. Vrhovsek, and F. Mattivi. 2015. Is there room for improving the nutraceutical composition of apple? J. Agr. Food Chem. 63:2750-2759.

Ferree, D.C. and I.J. Warrington (eds.). 2003. Apples: Botany, production and uses. CABI Publishing, Wallingford, UK.

Georgiou, A. 2009. Evaluation of rootstocks for the cyprus local lemon variety 'Lapithkiotiki'. Sci. Hort. 123:184-187.

Gheyas, F., E. Young, S.M. Blankenship, and R.F. McPeeters. 1996. Dietary fiber composition of 'Starkspur Supereme Delecious' apple fruit as influenced by rootstock and growing region. Fruit Var. J. 50:34-51.

Golding, J.B., W.B. McGlasson, S.G. Wyllie, and D.N. Leach. 2001. Fate of apple peel phenolics during cool storage. J. Agr. Food Chem. 49:2283-2289.

Hyson, D.A. 2011. A comprehensive review of apples and apple components and their relationship to human health. Adv. Nutr. 2:408-420.

Johnston, J.W., E.W. Hewett, N.H. Banks, F.R. Harker, and M.L.A.T.M. Hertog. 2001. Physical change in apple texture with fruit temperature: effects of cultivar and time in storage. Postharvest Biol. Technol. 23:13-21.

$\mathrm{Ju}, \mathrm{Z}$. and W.J. Bramlage. 1999. Phenolics and lipidsoluble antioxidants in fruit cuticle of apples and their antioxidant activities in model systems. Postharvest Biol. Technol. 16:107-118.

Ju, Z. and W.J. Bramlage. 2001. Developmental changes of cuticular constituents and their association with ethylene during fruit ripening in 'Delicious' apples. Postharvest Biol. Technol. 21:257-263.

Kaja, E., M.W. Szcześniak, P.J. Jensen, M.J. Axtell, T. McNellis, and I. Makałowska. 2015. Identification of apple miRNAs and their potential role in fire blight resistance. Tree Genet. Genomes 11:1-11.

Kevers, C., J. Pincemail, J. Tabart, J.O. Defraigne, and J. Dommes. 2011. Influence of cultivar, harvest time, storage conditions, and peeling on the antioxidant capacity and phenolic and ascorbic acid concentrations of apples and pears. J. Agr. Food Chem. 59:6165-6171.

Koch, K. and H.J. Ensikat. 2008. The hydrophobic coatings of plant surfaces: Epicuticular wax crystals and their morphologies, crystallinity and molecular self-assembly. Micron 39:759-772.

Kweon, H.J., I.K. Kang, M.J. Kim, J. Lee, Y.S. Moon, C. Choi, D.G. Choi, and C.B. Watkins. 2013. Fruit maturity, controlled atmosphere delays and storage temperature affect fruit quality and incidence of storage disorders of 'Fuji' apples. Sci. Hort. 157:60-64.

Lelièvre, J.M., A. Latchè, B. Jones, M. Bouzayen, and J.C. Pech. 1997. Ethylene and fruit ripening. Physiol. Plant. 101:727-739.

Lv, Y., I.I. Tahir, and M.E. Olsson. 2015a. Factors affecting the concentration of the ursolic and oleanolic acid in apple peel: Influence of cultivars, sun-exposure, storage conditions, bruising and Penicillium expansum infection. J. Sci. Food Agr. 96:2161-2169.

Lv, Y., I.I. Tahir, and M.E. Olsson. 2015b. Changes in the triterpene concentration during storage of three cultivars. Acta Hort. (ISHS) 1071:365-368.

Mahlo, S.M., L.J. McGaw, and J.N. Eloff. 2013. Antifungal activity and cytotoxicity of isolated compounds from leaves of Breonadia salicina. J. Ethnopharmacol. 148:909-913.

McGuire, R.G. 1992. Reporting of objective colour measurements. Hort. Sci. 27:1254-1255. 
Modgil, M., N. Guleria, M. Ghani, and J.N. Sharma. 2012. Identifying somaclonal variants of the apple rootstock Malling 7 resistant to white root rot. Sci. Hort. 137:148-155.

Morice, I.M. and F.B. Shorland. 1973. Composition of the surface waxes of apple fruits and changes during storage. J. Sci. Food Agr. 24:1331-1339.

Nisbet, A.J. 2000. Azadirachtin from the neem tree Azadirachta indica: Its action against insects. Ann. Soc. Entomol. Bras. 29:615-632.

Patil, B.S., D. Byrne, K. Crosby, and K. Hirschi. 2014. The intersection of plant breeding, human health, and nutritional security: lessons learned and future perspectives. HortScience 49:116-127.

Pensec, F., C. Pączkowski, M. Grabarczyk, A. Woźniak, M. Bénard-Gellon, C. Bertsch, J. Chong, and A. Szakiel. 2014. Changes in the triterpenoid concentration of cuticular waxes during fruit ripening of eight grape (Vitis vinifera) cultivars grown in the Upper Rhine Valley. J. Agr. Food Chem. 62:7998-8007.

Qi, S., L. Ding, K. Tian, X. Chen, and Z. Hu. 2006. Novel and simple nonaqueous capillary electrophoresis separation and determination bioactive triterpenes in Chinese herbs. J. Pharmaceut. Biomed. 40:35-41.

Robinson, T.L., A.N. Lakso, and S.G. Carpenter. 1991. Canopy development, yield, and fruit quality of 'Empire' and 'Delicious' apple trees grown in four orchard production systems for ten years. J. Amer. Soc. Hort. Sci. 116:179-187.

Rom, R.C. and R.F. Carlson (eds.). 1987. Rootstocks for fruit crops. Wiley-Interscience Publication, New York.

Rössle, C., H.H. Wijingaard, R.T. Gormley, F. Butler, and N. Brunton. 2010. Effect of storage on the concentration of polyphenols of minimally processed skin-on apple wedges from ten cultivars and two growing seasons. J. Agr. Food Chem. 58:1609-1614.

Rutkowski, K.P., D.E. Kruczynska, A. Czynczyk, and W. Płocharski. 2005. The influence of rootstocks M.9 and P 60 on quality and storability in 'Gala' and 'GalaMust' apples. J. Fruit Ornam. Plant Res. 13:71-78.

Salehzadeh, A., A. Jabbar, L. Jennens, S.V. Ley, R.S. Annadurai, R. Adams, and R.H.C. Strang. 2002. The effects of phytochemical pesticides on the growth of cultured invertebrate and vertebrate cells. Pest Mgt. Sci. 58:268-276.

Shanmugam, M.K., X. Dai, A.P. Kumar, B.K.H Tan, G. Sethi, and A. Bishayee. 2013. Ursolic acid in cancer prevention and treatment: Molecular targets, pharmacokinetics, and clinical studies. Biochem. Pharmacol. 85:1579-1587.

Streif, J. 1996. Optimum harvest date for different apple cultivars in the 'Bodensee' area, in determination and prediction of optimum harvest date of apples and pears: Proceedings of a Meeting of the Working Group on Optimum Harvest Date (COST 94), 9-10 June 1994.
A. De Jager, D. Johnson, and E. Hohn (eds.). Brussels, p. 15-20.

Tahir, I. 2006. Control of pre- and postharvest factors to improve apple quality and storability. SLU-PhD Thesis, Plant Breeding Dept., Swedish Univ. of Agr. Sci., Alnarp, Sweden.

Talluto, G., V. Farina, G. Volpe, and R. Lo Bianco. 2008. Effects of partial rootzone drying and rootstock vigour on growth and fruit quality of 'Pink Lady' apple trees in Mediterranean environments. Austral. J. Agr. Res. 59:785-794.

Tromp, J., A.D. Webster, and S.J. Wertheim. 2005. Fundamentals of temperate zone tree fruit production, p. 156-175. Backhuys Publisher, Leiden, The Netherlands.

Veraverbeke, E.A., J. Lammertyn, S. Saevels, and B.M. Nicola. 2001. Changes in chemical wax composition of three different apple (Malus domestica Borkh.) cultivars during storage. Postharvest Biol. Technol. 23:197-208.

Webster, A.D. 1995. Rootstock and interstock effects on deciduous fruit tree vigour, precocity, and yield productivity. N.Z. J. Crop Hort. 23:373-382.

Webster, A.D. 2001. Rootstocks for temperate fruit crops: Current uses, future potential and alternative strategies. Acta Hort. 557:25-34.

Yessoufou, K., H.O. Elansary, E.A. Mahmoud, and K. Skalicka-Wozniak. 2015. Antifungal, antibacterial and anticancer activities of Ficus drupacea L. stem bark extract and biologically active isolated compounds. Ind. Crops Prod. $74: 752-758$. 